\title{
GÊNERO, VIOLÊNCIA E INDÚSTRIA DO PETRÓLEO: UM PANORAMA DO IMPACTO DA REFINARIA DE DUQUE DE CAXIAS (REDUC) SOBRE A VIDA DAS MULHERES DA BAIXADA FLUMINENSE
}

\author{
Marcelo Aranda Stortti ${ }^{1}$ \\ Leila Salles Costa ${ }^{2}$
}

\section{RESUMO}

Este artigo tem por objetivo apresentar um panorama sobre a violência sofrida pelas mulheres, no campo socioeconômico que atingi diretamente a saúde, a economia doméstica e a vida dessas pessoas que vivem na região onde está instalada a indústria do petróleo, especificamente as que residem na região onde foi implantada a Refinaria de Duque de Caxias - REDUC. Para levantar os dados dessa pesquisa utilizamos a metodologia história oral. Como resultados, identificamos vários tipos de violações dos direitos das mulheres causados pela indústria do petróleo em Duque de Caxias na Baixada Fluminense tais como: aumento da prostituição, as explorações sexuais, a gravidez precoce de jovens da comunidade por trabalhadores da cadeia produtiva do petróleo, o aumento de casos de doenças sexualmente transmissíveis, como a AIDS; a diminuição da renda familiar e a falta de qualificação profissional e respectiva desocupação. A partilha injusta de direitos, recursos e poder, bem como, regras e normas culturais repressivas, constrangem a capacidade de muitas pessoas para agir diante de uma injustiça socioambiental. Isto é especialmente verdade para as mulheres. Por conseguinte, gênero é um fator essencial para entender a vulnerabilidade desse grupo social a uma injustiça socioambiental.

Palavras-chave: Gênero. Racismo Ambiental. Conflitos Ambientais. Petróleo.

${ }^{1}$ Coordenador e professor do Departamento de Biologia e Professor do Departamento de Educação da Faculdade de Filosofia, Ciências e Letras de Duque de Caxias. Email: marceloarandas@globomail.com

${ }^{2}$ Professora da Fundação Educacional Duque de Caxias. Email:

leilasalles03@gmail.com 


\section{ABSTRACT}

This article aims to present an overview of the violence suffered by women in the socioeconomic field that directly hit health, home economics, and the life of those people living in the region where the oil industry is installed, specifically those living in the region which was implemented Duque de Caxias - REDUC. To get the data from this survey used the oral history methodology. As a result, we identify several types of violations of women's rights caused by the oil industry in Duque de Caxias in the baixada fluminense such as increased prostitution, sexual explorations, early pregnancy community youth workers for the oil production chain, the increase in cases of sexually transmitted diseases such as aids; decreased family income and the lack of professional qualification and their eviction. The unfair sharing of rights, resources and power, as well as rules and repressive cultural norms constrain the ability of many people to act before an environmental injustice. This is especially true for women. Therefore, gender is essential to understand the vulnerability of this group to a social injustice environmental factor.

Keywords: Gender. Environmental Racism. Environmental Conflicts. Oil. 


\section{Introdução}

A indústria do petróleo surgiu no Brasil em 1953 com a criação da empresa brasileira de petróleo a Petrobras. No seu primeiro ano de funcionamento a Petrobras produziu 2.700 barris/dia de petróleo e refinaram somente $150 \mathrm{mil}$ barris/dia de derivado (ISTO É, 2005). Nestes 61 anos de atividades essa empresa registrou novos recordes, tanto, na produção, isto é, $273 \mathrm{mil}$ barris/dia de petróleo, bem como, no refino 2 milhões barris/dia de derivados (AGÊNCIA NACIONAL DO PETRÓLEO, GÁS NATURAL E BIOCOMBUSTÍVEIS, 2013). Porém no campo socioambiental será que poderemos também ter motivos para comemorar?

A exploração, extração, refino e transporte de petróleo (atividades da indústria) em terra e no mar, muda o meio ambiente e a vida das pessoas que vivem nas áreas onde ocorrem estas atividades. Os impactos socioambientais são muitos e variados. Para citar alguns exemplos: produção de lixo, emissões de gases e vazamentos que contaminam e degradam os mares e as praias, alterações na qualidade da água e do ar, contaminação de lençóis freáticos (fontes de água abaixo da terra), interferência nas rotas de migração e período reprodutivo de peixes e da fauna aquática e destruição de manguezais, além de ser uma das grandes causas das mudanças no clima. A indústria também expulsa populações dos seus territórios, destrói a pesca artesanal e a saúde de moradores e moradoras do local onde ela se instala, aumenta o índice de violência doméstica. Além disso, a organização social e econômica da sociedade regional é transformada pela indústria do petróleo. Um exemplo vivo desta situação na Baixada Fluminense, foi à implantação da refinaria de petróleo e o Pólo petroquímico da REDUC na década de 1960 como cita Raulino,

A chegada da Petrobrás em Duque de Caxias mudou a história da Cidade, dos municípios da Baixada e também das cercanias da Baía de Guanabara. "não houve o planejamento urbano necessário para receber as populações migrantes que vinham dos sentidos centro/periferia e campo/cidade trabalhar na REDUC”. Como resultado de todo esse processo, a população do entorno da refinaria estaria mais exposta a uma gama de situações consideradas de risco/danosas tais como: habitações precárias, em locais com riscos de enchentes, falta de equipamentos públicos de saúde, abastecimento regular de água tratada e de outras ações de saneamento, que se somam aos riscos de vazamentos de óleo (como os de 1998 e 2000), gases (como o de alumínio silicato de sódio, o "pó branco", em 2001, e o de GLP em 2011), lançamento de efluentes 
industriais nos rios e Baía de Guanabara, contaminação de solos, transporte de cargas perigosas, proximidade de oleodutos e gasodutos, áreas de armazenamento de combustíveis e outros derivados do petróleo, emissões gasosas poluentes, explosões e incêndios (como os de 1972) (RAULINO, 2013, p. 169).

Essas situações são características das desigualdades ambientais que apontam para as injustiças ambientais, problematizadas por ACSERALD, 2009. Ainda assim, com diversos projetos ambientais e sociais, a Petrobras é considerada por muitos como uma empresa exemplar. É tratada pelo governo brasileiro como estratégica para a expansão de empresas brasileiras em outros países, e por isso conta com forte apoio e financiamento do Banco Nacional de Desenvolvimento Econômico e Social (BNDES). A empresa, que está atuando em vários países pelo mundo, é alvo de diversas denúncias de conflitos ambientais nos lugares onde se instala.

No Brasil as denúncias vão desde impactos ambientais em áreas de preservação ambiental, como foi à instalação de gasoduto na Reserva Biológica do Tinguá, em Duque de Caxias no Rio de Janeiro, sem sequer repor a florestal desmatada na área, como estabelece a legislação ambiental; "financiamento" de trabalho escravo da empresa Brasil Ecodiesel, fornecedora de biodiesel em Canto do Buriti no Piauí; uso de equipamentos fora das condições adequadas de segurança, colocando em risco a vida de trabalhadores em Bacia de Campos (RJ) - foram mais de 300 mortes de trabalhadores ligados a empresa em 16 anos; até a instalação do Terminal de Regência (Tereg) em Área de Preservação Ambiental Permanente (APP) em Linhares no Espírito Santo.

A empresa foi sentenciada por crime ambiental pelo vazamento de 1,3 milhões de litros de óleo da Refinaria Duque de Caxias (Reduc-RJ) na Baía de Guanabara em 2000 e por crime de poluição na região de Campinas, onde funciona a Refinaria de Paulina (Replan, SP). Segundo Cesário (2002) Bilhões são jogados nos rios, nos mares, nas lagoas, na atmosfera, devido aos vazamentos constantes dos dutos da Petrobras por erros propositais das gerências comprometidas com o absurdo do lucro a qualquer custo.

Além disso, essa empresa está ainda envolvida em conflitos ambientais com comunidades quilombolas e campesinas, como no caso da refinaria Premium, no Maranhão. A Amazônia é atualmente alvo de 
atividades de expansão da indústria petroleira e da empresa, onde o Acre se destaca pelos conflitos e processos de resistências.

A partir do contexto apresentado, destinamos um olhar singular para a questão da violação dos direitos humanos das mulheres sobre o sistema econômico da indústria do petróleo e o ponto de vista sobre as transformações que são impostas pelo modelo capitalista de produção, consumo e troca que também é ponto de pauta desta leitura.

Não só em Duque de Caxias - RJ, com a REDUC, mas em todos os lugares do mundo onde a indústria do petróleo explora, sabemos os danos que ela causa a população que ali reside como também a todo o ecossistema do planeta. Um exemplo recente é o caso da Nigéria, onde as mulheres foram para as ruas protestar, pois sem água para o consumo, foram atingidas diretamente na saúde e na produção do viver, conforme publicação da Avaaz:

Após um vazamento na unidade de exploração de petróleo da Shell em Bonga, em dezembro do ano passado, milhões de barris de petróleo foram derramados no oceano e espalhados pela região costeira altamente populosa - isso resultou em um dos maiores derramamentos de petróleo da África. As empresas de petróleo já lucraram US\$600 bilhões de dólares nos últimos 50 anos na Nigéria, mas os habitantes nunca se beneficiaram disso. Suas terras, água potável e áreas de pesca estão arruinadas. O Pnuma afirma que a água potável em algumas áreas foi contaminada tão gravemente que precisa de ação de emergência imediata. O levantamento foi feito ao longo de um período de 14 meses, com visitas a $122 \mathrm{~km}$ de oleodutos e a revisão de mais de 5 mil registros médicos, envolvendo mais de 23.000 pessoas em reuniões locais (AVAAZ, 2012).

Como considerar avanços no processo de solidariedade quando vimos que o sistema capitalista não leva em consideração outras visões de mundo sobre o funcionamento da vida de mulheres que também garantem a reprodução material da vida?

A lógica de mercado não é a única lógica do funcionamento da economia. A partir dessa consideração e, dialogando com mulheres da classe trabalhadora e moradoras da Baixada Fluminense, que participam de organizações de mulheres, e do Fórum dos Atingidos pela indústria do petróleo e petroquímica nas cercanias da Baía de Guanabara-FAPP-BG, percebemos o quanto essas mulheres têm sido impactadas diretamente pela indústria do petróleo e petroquímica. A posição das mulheres, enquanto grupo, é caracterizada pela pobreza, 
pela exclusão e pela violência, onde suas formas e intensidades variam de acordo com as empresas que são implantadas na localidade onde moram.

\section{Revisão Bibliográfica e Referencial Teórico}

Acserald (2005) afirma que o termo ambiente tem sido construído como objeto epistêmico, e identificado como tema concernente às pesquisas em ciências sociais e particularmente na sociologia recentemente. Isso fica evidencia com as pesquisas de Riley Dunlap (1979 e 2002) e Willian Catton (1979).

Para Fleury; Almeida; Premebida (2014, p.36) o surgimento do ambiente como campo de estudos está relacionado a

um processo de demanda por análises teóricas capazes de
articular o social e o natural, podendo-se identificar na
constituição daquela que se convencionou chamar
de sociologia ambiental um de seus primeiros acolhimentos.
Contudo, pouco a pouco distintas áreas da sociologia
começaram a incorporar temáticas ambientais em suas
problematizações, compondo um amplo leque de
interpretações sobre as interfaces entre sociologia e ambiente.

Buttel (1987) organizou uma revisão sobre o campo da sociologia ambiental, dialogando com a revisão feita por Dunlap; Cantton (1979), e debatendo sobre os conceitos teóricos dessa sociologia. Buttel (1987), também, demonstrou que essa sociologia é uma mistura de áreas e subdisciplinas, até aquele momento, tais como: ecologia humana, sociologia rural e a sociologia dos recursos naturais. E essas estariam relacionadas com os comportamentos e atitudes ambientais e com o movimento ambiental.

Herculano (2000) revisa o trabalho de Buttel (1996) e afirma que deveríamos acrescentar a psicologia social e a antropologia cultural, sociologia dos movimentos sociais, sociologia do desenvolvimento e a sociologia urbana.

Alonso e Costa (2002) apresentam vários autores que se propuseram a fazer revisões sobre o campo das ciências sociais e meio ambiente. Segundo esses dois autores as pesquisas nessa área estavam focadas na sociologia ambiental e a de recursos naturais. Alonso e Costa 
(2002) explica, ainda, que o interesse dos pesquisadores brasileiros nessa área começa a aumentar após a o Fórum Mundial das Nações Unidas (RIO 92). Para esses autores o aumento de pesquisas originou uma diversificação temática, definidas em três abordagens temáticas: estudos de meio ambiente e políticas; estudos sobre políticas públicas e participação e estudos culturais.

Esses autores argumentam que essa abordagem: meio ambiente e políticas está voltada para a análise dos discursos e ações ambientalistas sob três pontos de vista: "movimento social; como parte de um processo político global; e como foco de um novo tipo de conflito social (ALONSO; COSTA, 2002, p.8)".

Alonso e Costa (2002) apontam como a gênese das pesquisas desse novo tipo de conflito social, o ambiental, os trabalhos de Jacobi (1995), Herculano (1994), Fucks (1998) e Costa; Alonso; Tomiaka (1999; 2000). Para os autores anteriormente citados essas pesquisas se focam na publicitação dos conflitos, bem como, no mapeamento dos atores, arenas, processos, constituição e resolução dos conflitos ambientais.

Acserald (1993) busca construir uma definição de conflitos ambientais, afirmando que são aqueles em que as comunidades são atingidas por um processo de degradação ambiental. Ele ainda destaca que esse tipo de conflito pode ser dividido em dois tipos: explícitos e implícitos. Ele explica que o primeiro está relacionado a tomada de consciência por um grupo social que um direito ambiental foi desrespeitado, estabelecendo uma relação lógica entre os danos ao meio ambiente e a atuação de agentes sociais. E o segundo tipo está relacionado à ausência de consciência ou clareza entre a relação da ação de agente social e a degradação ambiental (ACSERALD, 1993).

Em 1994 foi organizado no Brasil o primeiro seminário conflitos sociais e meio ambiente reunindo pesquisadores de diferentes universidades do Brasil, uma dos Estados Unidos e diversas ONGs e representantes de movimentos sociais. Esse seminário teve como objetivo discutir e construir uma matriz teórico-metodológica para a compreensão das lutas sociais em torno da questão ambiental (IBASE, 1996).

Desde esse primeiro encontro esse tema tem conquistado uma 
relevância nas pesquisas nacionais, sendo ratificada pelo envio de pesquisa e sua respectiva discussão nos principais encontros nacionais da área das Ciências Sociais, tais como: encontros da Associação Nacional de Pesquisas e Pós-Graduação em Ambiente e Sociedade (ANPPAS), na reunião da Associação Nacional de Pesquisa e Pós-Graduação em Ciências Sociais (ANPOCS), entre outros.

A partir desse universo de diversas pesquisas Fleury; Almeida; Premebida (2014), fazem uma revisão atualizada sobre esse campo e afirmam que podemos identificar três grupos de abordagens do campo de pesquisa em conflitos ambientais no Brasil, tais como: a sociologia ambiental; sociologia crítica e a antropologia. Porém, a partir da sociologia americana Bullard (2002) apresentou novas ideias sobre os conflitos ambientais descrevendo o nascimento do movimento de justiça ambiental nos Estados Unidos. No entanto, em apenas duas décadas, este movimento popular se espalhou por todo o globo.

A chamada para a justiça ambiental pode ser ouvido a partir do gueto de Southside Chicago para o município Soweto. $\mathrm{O}$ movimento de justiça ambiental já percorreu um longo caminho desde seu humilde início em 1982, em Warren County, Carolina do Norte, onde um aterro PCB inflamados protestos e mais de 500 prisões.

O racismo ambiental refere-se à política ambiental, prática ou diretiva que afeta diferencialmente ou desvantagens (se intencional ou não intencional) indivíduos, grupos ou comunidades com base na raça ou cor. O racismo ambiental é reforçado pelo governo, as instituições jurídicas, econômicas, políticas e militares. $\mathrm{O}$ racismo ambiental se combina com políticas públicas e práticas da indústria para fornecer benefícios para os países do Norte enquanto a mudança de custos para os países do sul.

Segundo Bullard (2002) O racismo ambiental reforça a exploração da terra, as pessoas e o ambiente natural. Ele funciona como um arranjo de poder intra-nação especialmente onde os grupos étnicos ou raciais formam uma minoria política e ou numérica. 
No Brasil as questões relacionadas à justiça ambiental começam a ser debatida através da publicação em 2000 do livro Sindicalismo justiça ambiental (ACSERALD, HERCULANO, PÁDUA, 2004).

Em 2001 esse debate ganha força com o Colóquio Internacional sobre Justiça Ambiental (ibid., 2003.p.13). Neste mesmo evento ocorre a criação da Rede Brasileira de Justiça Ambiental. Essa Rede reúne pesquisadores, universidades, sindicatos, ONGs, movimentos sociais que buscam publicita as formas de injustiças que ocorrem no país e trocam experiências e conhecimentos para construir uma democracia justa e participativa.

Acserald (2010) explica que as entidades e os movimentos que começaram, no Brasil, a partir dos anos 2000, a associar sua ação à noção de "justiça ambiental" inserem-se, por certo, nesse grupo mais combativo que profissional mais envolvido na discussão crítica das políticas Públicas do que no assessoramento técnico a governos e empresas.

Como já mencionamos anteriormente as pesquisas nesse campo tem aumentado no Brasil, como podemos observar ao investigar quantos grupos de pesquisas do CNPQ que se dedicam a esse tema. Porém, a maioria das pesquisas está focada na publicitação dos conflitos e das injustiças ambientais, algumas focadas nos grupos sociais, tais como: índios, atingidos por barragens etc., porém nenhuma pesquisa estava voltada para a questão de gênero e esse campo.

A partir dessa pesquisa, buscamos refletir sobre as questões de gênero de moradoras próximo de uma refinaria do petróleo localizada no município de Duque de Caxias, Rio de Janeiro.

\section{Metodologia}

Esta pesquisa foi realizada por conta da participação dos autores no Fórum dos Atingidos pela Indústria do Petróleo e Petroquímica nas cercanias da Baía de Guanabara, bem como, de pesquisas socioambientais na região, onde conhecemos mulheres fascinantes que lutam com coragem e determinação, que se tornaram os sujeitos da pesquisa. Utilizou-se a metodologia da história oral, (MARCONI e 
LAKATOS, 1999), pois a partir das histórias de vida dessas mulheres teríamos um olhar privilegiado das experiências e lutas vivenciadas por esse grupo social.

Nessa pesquisa realizamos quatro encontros (rodas de conversas) com esse grupo de mulheres, onde registramos as falas das mulheres em uma agenda. Além disso, durante os encontros deixávamos o notebook ligado e gravávamos as conversas por meio do programa de computador OneNote. Essa escolha foi feita pela descrição durante a gravação, pois se colocássemos um gravador ou algum outro aparelho as mulheres ficariam inibidas em contar as suas histórias.

Esse grupo era formado por 10 mulheres, cujos filhos estudavam na creche municipal de Campos Elísios para crianças desnutridas. Elas tinham idade entre 22 a 42 anos e moravam na localidade a mais de 10 anos. A maioria delas não tinha emprego fixo, ganhava em média um salário mínimo no mês quando conseguiam algum tipo de serviço.

\section{Resultados}

Um grave caso de violação dos direitos das mulheres causado pela indústria do petróleo em Duque de Caxias na Baixada Fluminense é o caso do aumento da prostituição descrito por Raulino, 2009, na sua tese de doutorado, em entrevista com a coordenadora do Centro de Referência Patrimonial e Histórico do Município de Duque de Caxias, Marlúcia Souza, sobre os denominados pela população de baianinhos, a saber:

Dois entrevistados, entre eles uma dirigente do Sindicato Estadual dos Profissionais da Educação em Duque de Caxias (SEPE - Caxias) e Coordenadora do Centro de Referência Patrimonial e Histórico do Município de Duque de Caxias (CRPH) relataram que o grande fluxo de trabalhadores terceirizados a que vem trabalharem de outros estados na refinaria e nas obras de instalação/ampliação de empreendimentos leva à prostituição na vizinhança da REDUC e ao conseqüente nascimento de crianças que não conhecem seus pais, chamados "baianinhos", como se percebe no relato abaixo:

[...] Mas o povo de Campos Elíseos só ficou com a herança, que foi os baianinhos, os mineirinhos, que são aqueles que choram nos colinhos das nossas meninas aqui da região. Então o que aumentou muito foi à prostituição, em virtude do 
crescimento dessa população. "E aí, como ambientalista eu digo sempre o seguinte, o impacto social foi muito maior que a morte das lagartixas, morreu pouco sapo" (Coordenador da SCC em entrevista individual em 09 de abril de 2008, apud RAULINO, 2013, p.190).

Seriam essas crianças filhas e filhos do petróleo?

A violação dos direitos humanos é quando o visível crescimento do mercado do sexo onde a prostituição e as explorações sexuais se agravam com a instalação destas empresas e atingem diretamente a vida das mulheres que ali residem onde o aumento do número de trabalhadores oriundos de outros estados e até mesmo de outros países para o local da obra, gerando um alto índice de doenças sexualmente transmissíveis como as DST'S/AIDS em mulheres e jovens adolescentes. , conforme descrito também por Raulino

Outros dois entrevistados (Paróquia São Francisco de Assis) apontaram a propagação do vírus da AIDS na região como também sendo causada pelo processo acima mencionado. Uma das comunidades mais atingidas seria Vila Serafim [...], segundo os relatos ouvidos (RAULINO, 2009, p. 203).

O que nos chama mais atenção é que constantemente as mulheres refletem e vivenciam a partir de situações marcadas pelas desigualdades ou pela exclusão, o que não é diferente neste contexto que estamos redigindo, pois, lá estavam elas à frente de todos os espaços de resistências que foram visitados, sabendo da importância de se apresentarem os problemas locais como a falta de água, saneamento básico, doenças, contaminações entre outros problemas porque quando as doenças são acometidas em seus filhos, maridos ou parentes, são elas que farão o trabalho do cuidado com a saúde, alimentação e, até mesmo no caso de ameaças de morte ou a fatalidade quando acontecem, são as que mais sofrem com isso. São elas as que carregam "as latas d'água na cabeça".

Esses impactos socioambientais atingem diretamente a vida cotidiana da população e principalmente das mulheres, pois, quando os da casa adoecem são elas as que deixam de ir ao trabalho, passam noites sem dormir para dar conta dos afazeres domésticos e dos que residem no mesmo teto.

A piora nas condições sanitárias e com ela a presença de doenças e escassez ou poluição dos elementos necessários para o consumo e 
qualidade de vida, impactam diretamente o trabalho e a vida das mulheres. Para CARRASCO,

A análise das necessidades de reprodução das pessoas é um tema complexo, que pode ser abordado a partir de diferentes perspectivas, áreas temáticas ou disciplinas. Mas, em qualquer caso, é um tema central. No entanto, em uma perspectiva socioeconômica, pelo menos para a economia oficial, a sustentabilidade da vida não tem sido nunca uma preocupação analítica central; ao contrário, usualmente é considerada uma "externalidade" ao sistema econômico (SOF, 2003, p.12).

\section{Considerações finais}

Martinez-alier (2007) explica que os diversos conflitos envolvendo a indústria de petróleo têm chamado a atenção de pesquisadores e instituições de pesquisa principalmente no que diz respeito à luta de populações locais em defesa de seus territórios e a aclamação por soluções sustentáveis para a sociedade e meio ambiente.

Outras pesquisas apontam na direção que:

a sustentabilidade das regiões produtoras de petróleo precisa ser eco eficiente e justa socialmente e para isso os gestores precisam prover meios de garantir a participação das comunidades em decisões sobre empreendimentos que afetem a sustentabilidade ambiental e social, visto que, os caminhos da economia ainda estão longe de romper com o mercado da energia baseada nos combustíveis fósseis (RAMOS, 2009, p. 20)

Giddens (1996, p. 256) corrobora com a ideia da homogeneização dos problemas ambientais afirmando que a ecotoxicidade afeta a todos, produzindo uma contaminação genérica. Porém Bullard (2002) afirma que a busca pelo desenvolvimento sustentável deve abordar as causas profundas da pobreza e da poluição e buscar soluções para essa ameaça dupla.

Aprofundando esse debate Acserald (2009) afirma que os jornais difundem a ideia que estamos todos igualmente sujeitos aos efeitos nocivos de uma crise ambiental. Esse autor, afirma que é possível constatar que: "sobre os mais pobres e os grupos étnicos desprovidos de poder recai, desproporcionalmente, a maior parte dos riscos ambientais socialmente induzidos" (ACSERALD, 2009. p.12). 
Nesta pesquisa, podemos contribuir com as reflexões acima apresentadas afirmando que além das questões de pobreza e de grupos étnicos, a questão de gênero reforça a ideia da desigualdade que estão expostos as mulheres em relação aos homens. Sendo necessário aprofundar a reflexão sobre os caminhos para diminuir essas desigualdades.

A vulnerabilidade aos conflitos socioambientais é determinada em grande parte pela capacidade de enfrentamento, mobilização e participação das pessoas. Uma calamidade industrial ou tecnológica particular, a construção de uma indústria, uma explosão, vazamento químico, pode não afetar todas as pessoas numa mesma comunidade ou até no mesmo grupo familiar, pois algumas pessoas têm maior capacidade que outras para responder diante de uma injustiça socioambiental.

A partilha injusta de direitos, recursos e poder, bem como, regras e normas culturais repressivas, constrangem a capacidade de muitas pessoas para agir diante de uma injustiça socioambiental. Isto é especialmente verdade para as mulheres. Por conseguinte, gênero é um fator essencial para entender a vulnerabilidade a uma injustiça socioambiental.

\section{Referências}

ACSELRAD, H. Apresentação. In: Andréa Zhouri. (Org.). A insustentável leveza da política ambiental. Belo Horizonte: Autêntica, 2005.

ACSELRAD, H.. Ambientalização das lutas sociais - o caso do movimento por justiça ambiental. Estudos Avançados. 24 (68), 2010.

ACSELRAD, H. (Org.). Conflito social e meio ambiente no Estado do Rio de Janeiro. Rio de Janeiro: Relume Dumará: FASE, 2004.

ACSELRAD, H.; MELLO, C.C. A.; BEZERRA, G. N. O que é justiça ambiental. Rio de janeiro: Garamond, 2009.

ACSELRAD, H.; VIEIRA, L.; GUARANY, R.. Ecologia direito do 
cidadão. Rio de Janeiro: Gráfica JB, 1993.

ACSELRAD, H.; HERCULANO, S.; PADUA, J.A.. Justiça ambiental e cidadania. Rio de Janeiro: Relume Dumará: Fundação Ford, 2004.

AGÊNCIA NACIONAL DO PETRÓLEO, GÁS NATURAL E BIOCOMBUSTÍVEIS (BRASIL). Anuário Estatístico Brasileiro do Petróleo, Gás Natural e Biocombustíveis. Rio de janeiro. 2013.

ALONSO, Ângela; COSTA, Valeriano. Por uma sociologia dos conflitos ambientais no Brasil. Buenos Aires: CLACSO, Consejo Latinoamericano de Ciencias Sociales, 2002. Disponível em: <http://bibliotecavirtual.clacso.org.ar/clacso/gt/20100930023420/7alo nso.pdf>. Acesso em: 12 mai. 2009.

ALONSO, Ângela; COSTA, Valeriano. Ciências sociais e meio ambiente no Brasil: um balanço bibliográfico. Revista Brasileira de Informações Bibliográficas em Ciências Sociais, ANPOCS. 53, pp. 35-78. 2002.

AVAZZ.org. O poder das pessoas versus indústrias petrolíferas. 2012. Disponível em: http://www.avaaz.org/po/make_shell_pay_rb/?bqwbrbb\&v=19283. Acesso em: 17 junho 2014.

BUTTEL, F. H.. New directions in Environmental Sociology. Ann. Rev. Sociol. 13. 465- 488. 1987.

CARRASCO, Cristina; MIRANDA, Maria; PARERAS, Anna; MEDRANO, Hortênsia Fernández; SAENZ, Neus Moreno. Malabaristas de la vida. Mujeres, tiempos y trabajos. Icaria. Barcelona, 2003.

CESARIO, N.V.. Trabalhadores da Petrobras e risco ambiental na Baía da Guanabara. IN: FILHO, W.M. (Org.). Direito e Justiça ambiental. Rio de Janeiro: Universidade Federal Fluminense, 2002. P. 111-128.

DUNLAP, R. E. Paradigms, Theory and Environmental Sociology In: DUNLAP, R. E., BUTTEL, F. H., Dickens, P. e GIJSWIJT, A. (Org.), 
Sociological Theory and the Environment. Classical Foundations, Contemporary Insights, NY/Oxford/Lanham/Boulder, Rowman \& Littlefield Publishers, 2002. p. 331.

DUNLAP, R. E. e CATTON, W. R. Environmental Sociology. Annual Review of Sociology. no 5, p. 252. 1979.

FLEURY, Lorena Cândido; ALMEIDA, Jalcione; PREMEBIDA, Adriano. O ambiente como questão sociológica: conflitos ambientais em perspectiva. Sociologias, Porto Alegre, v. 16, n. 35, abr. 2014 . Disponível

<http://www.scielo.br/scielo.php?script=sci_arttext\&pid=S1517-

45222014000100003\&lng=pt\&nrm=iso>. Acesso em 23 jun. 2014.

FORUM DOS ATINGIDOS PELA INDÚSTRIA DO PETROLEO E PETROQUIMICA NAS CERCANIAS DA BAÍA DE GUANABARA. 50 anos da Refinaria Duque de Caxias e a expansão da indústria petrolífera no Brasil: Conflitos socioambientais no Rio de Janeiro e desafios para o país na era pré-sal. Rio de janeiro: Fundação Heinrich Boll: FASE, 2013.

FUKS, M.. Conflitos Ambientais no Rio de Janeiro: ação e debate nas arenas públicas. Rio de Janeiro: Editora UFRJ, 2001.

IBASE. Conflitos sociais e meio ambiente: desafios políticos e conceituais. Rio de Janeiro: Fundação Heirinch-Boll-stiftung, 1996.

ISTO É (BRASIL). O Petróleo é todo nosso. São Paulo, 2005.

COSTA, Leila Salles e QUINTELA Sandra. Economia Política nas mãos das mulheres. Uma experiência de educação popular. PACS. Rio de Janeiro, 2010.

MARCONI, M. A; LAKATOS, E. M. Técnicas de pesquisa: planejamento e execução de pesquisas, amostragens e técnicas de pesquisa e elaboração, análise e interpretação de dados. São Paulo: Ed. Atlas, 1999.

MARTINEZ-ALIER, J. O ecologismo dos pobres. Editora Contexto, São Paulo, 2007.

RAMOS, M. S.. Indicadores de impactos da indústria de petróleo: 
estudo de caso da região polarizada pelo município de Macaé. 2009. 142 f. Dissertação (Mestrado em Engenharia Ambiental) - Instituto Federal de Educação Ciência e Tecnologia Fluminense, Campos dos Goytacazes, Rio de Janeiro, 2009.

RAULINO, S. F.. Construções sociais da vizinhança: temor e consentimento nas representações dos efeitos de proximidade entre grandes empreendimentos industriais e populações residentes. 2009. 338 f. Tese (doutorado em Planejamento Urbano e Regional) - Universidade Federal do Rio de Janeiro, Rio de Janeiro, 2009.

SOF. A produção do Viver: Ensaios de Economia Feminista. NOBRE, Miriam, FARIA, Nalu (orgs.). Cadernos Sempreviva. São Paulo, 2003. 